\title{
Competência do pensamento histórico, domínio de um panorama histórico ou conhecimento do cânone histórico ${ }^{1}$
}

\section{Competence of historical thinking, mastering of a historical framework, or knowledge of the historical canon?}

\author{
Bodo von Borries ${ }^{2}$
}

\begin{abstract}
RESUMO
A história é um assunto complexo com uma epistemologia complexa, oferecendo múltiplas e frequentes explicações contraditórias para e por que as coisas são como são hoje. Deve, portanto, ser pensada como "um modelo de pensamento" e não estritamente como uma narrativa cronológica ou cânone histórico, especialmente porque cronologias e cânones simplificam o passado, deixando de fora $99,9 \%$ do que aconteceu, particularmente experiências de pessoas comuns. Portanto, o ensino de História deveria construir competências do pensamento histórico. A história deve ensinar mais a partir de múltiplas perspectivas e deveria iniciar a partir das necessidades e experiências dos próprios alunos. A partir disso, o currículo poderia ir no sentido de explorar processos de mudança, eventos específicos de importância crítica para estudantes e pesquisas metodológicas. Para jovens e crianças, estudos de caso podem ser usados para constituir eventos mais concretos e significativos. Já os estudantes mais velhos podem estudar temas históricos e processos em um nível mais abstrato.

Palavras-chave: pensamento histórico; ensino de História; aprendizagem histórica.
\end{abstract}

DOI: $10.1590 / 0104-4060.45980$

1 Texto traduzido por Marcelo Fronza. Universidade Federal de Mato Grosso. Cuiabá, Mato Grosso, Brasil. Campus Cuiabá. Av. Fernando Corrêa da Costa, nº 2367. Bairro Boa Esperança. CEP: 78060-900.E-mail: fronzam34@yahoo.com.br

2 Universidade de Hamburgo. Hamburg, Alemanha. Alsterterrasse 1. 20354. E-mail: bvborries@aol.com 


\begin{abstract}
History is a complex subject with a complex epistemology, offering multiple and often contradictory explanations for and why things are the way they are today. It should therefore be thought of as "a model of thinking" rather than a strict chronological narrative or historical canon, especially because chronologies and canons oversimplify the past, leaving out $99.9 \%$ of what happened, particularly the experiences of common people. Therefore, History education must build historical thought competence. History must be taught from multiple perspectives, and should start from children's own needs and experiences. From there, the curriculum should go on to explore processes of change, specific events of critical importance to students, and research methodologies. For youngsters and children, case studies can be used to make events more concrete and meaningful. Older students can study historical themes and processes on a more abstract level.
\end{abstract}

Keywords: historic thought; teaching of History; historical learning.

\title{
O que a história quer dizer?
}

O que é "História", o que é "História Geral", o que é "História Relevante"? Essas três questões não são completamente idênticas, mas algo similares.

- História não é uma lista de fatos, uma história de eventos, processos e estruturas;

. História não é "o passado" ou "a mais importante parte do passado";

- História não é - por assim dizer, uma ilustração precisa - modelo, imitação, ou cópia do passado.

Ao contrário, história é um modo distinto de pensamento, um acesso metódico para um melhor entendimento do mundo e de si, uma ferramenta para decodificar fenômenos e orientações no presente e no futuro - basicamente efetuada por narrativas "verdadeiras" sobre eventos passados, mudanças e desenvolvimentos.

A típica questão clássica: "Papai, por que os austríacos não são alemães, apesar deles falarem alemão?" A questão não pode ser respondida por teorias sistemáticas ou argumentos lógicos, mas apenas contando uma história sobre diferentes estados no passado (eventos, processos, estruturas, evolução) e suas mudanças até hoje ("desenvolvimento"). Esta é chamada a "lógica narrativa" na estrutura da história. (LÜBBE, 1975). Certamente, o contar (produzir: "re-construção") histórias não é somente uma operação mental, mas o exame 
(análise: "des-construção") de versões históricas já completadas e oferecidas por outros é igualmente importante (veja a seguir).

No caso mencionado, várias e distintas histórias podem ser ditas. Uma é a do tipo tradicional "pessoas e eventos":

\begin{abstract}
A Áustria tem sido uma parte da Alemanha. Mas, então, Napoleão surgiu e o velho Sacro-Império Romano chegou ao fim. Depois sob Bismarck, foi colocada a Áustria fora da Alemanha (a "Federação Germânica" de 1815) pela guerra em 1866. Depois da Primeira Guerra Mundial, em 1919, os austríacos tentaram em vão juntar-se à Alemanha novamente, mas os aliados proibiram. Depois Hitler anexou a Áustria em 1938 e foi derrotado em 1945, o "staatsvertrag" (tratado de Estado), em 1955, fez da Áustria um "Estado Nacional" separado - e neste tempo foi aceito como de língua germânica. Em 1995 ela entrou na União Europeia, sem demandar uma linguagem austríaca adicional.
\end{abstract}

Mas uma outra história pode ser mais plausível:

A teoria ou ideologia de "uma linguagem - uma nação" - um estado, que é a base de sua questão sobre Áustria e Alemanha, historicamente evoluiu tarde, não antes do século XVIII e início do século XIX. Desde 1806, e ainda em 1866, a Áustria foi uma parte da Alemanha; mas a Alemanha não foi um "Estado Nacional" o tempo todo. Por mais ou menos razões acidentais, a Áustria estava economicamente e militarmente excluída dos processos da "construção nacional" alemã. Depois disso (em 1919 e 1938), algumas tentativas foram feitas de ambos os lados para integrar a Áustria tardiamente, mas elas falharam, por causa de duas derrotas em Guerras Mundiais e por causa de um gradual distanciamento entre os dois países.

A primeira versão é mais suave e menos teórica (uma "história dos eventos"); mas esta é menos "historicamente plausível", porque omite a essencial diferença de mentalidades e estruturas anteriores ao século dezenove. Torna-se possível construir uma terceira história sem muita dificuldade: "No caso alemão - como em outros, como na Bélgica, Grã-Bretanha e Estados Unidos - 'linguagem', 'Cultura', 'Estado' e 'Nação’ têm que ser distinguidos cuidadosamente. Por razões históricas a Áustria é linguisticamente (e culturalmente) alemã e politicamente (nacionalmente) não alemã." 
E uma quarta versão é ainda mais plausível:

A Áustria não é primariamente uma nação, uma tribo ou um território, mas uma dinastia ("Casa d'Áustria - Habsburgos") que se afirmou para reinar sobre todo o mundo ("AEIOU - Áustria Esta Imperiu Orbis Universi" - "toda a terra é súdita da Áustria"). No século XIX, era da "construção nacional", a Áustria transformou-se em um "Império transnacional" para uma assim chamada "prisão de nações". Depois disto caiu em 1918 e foi reduzida a um pequeno estado de língua Alemã (ou, ainda, um "microestado").

\section{A "história" não é identificável com a "história política" - e isto é essencial para entender o mundo}

O número de tais questões, que só podem ser respondidas historicamente e não logicamente, é enorme - e não somente no campo político das nações e Estados, mas em alguma parte e setor da vida pública e privada:

"Mãe, por que minha amiga Mary uma Católica (veste uma saia longa) e minha amiga Beyhan uma Muçulmana (usa um véu), enquanto eu sou uma garota protestante (e posso andar quase nua)?"

"Mr. Muller, por que nunca houve uma presidente mulher dos Estados Unidos?"

"Papai, por que meu nome é aquele da minha mãe Carla Neubeauer, enquanto meus colegas de classe são chamados Kaminsky e Öztürk, de acordo com os nomes de seus pais?"

"Papai, por que a maioria dos cidadãos norte-americanos fala inglês e os cidadãos mexicanos espanhol? Por que o primeiro grupo é mais rico e o segundo normalmente é pobre?"

"Mrs. Cohn, por que Hamburgo é um estado separado da Alemanha e Munique não?"

"Prof. Wheller, você pode, por favor, me dizer por que a família Flick possui bilhões de euros e minha família não?"

Todos esses fatos e condições do mundo apresentados podem somente ser explicados pela lógica, pela natureza ou por histórias, isto é, os efeitos contínuos 
de formas, eventos e processos. Se nós aceitássemos naturalmente como uma causa, nós facilmente chegaríamos ao racismo, biológico, Darwinismo Social ou determinismo. (LÉVI-STRAUSS, 1952). Neste caso, estruturas sociais e diferenças não podem ser distinguidas a partir do que elas são atualmente. Se nós escolhemos a "história" como uma explicação, nós fazemos o passado responsável pelo presente e nós temos que levar o "acaso" ou o "acidente" em conta ("contingencial"). Ao contrário, nós temos o problema da trivialidade ou dos argumentos circulares: "Explicações históricas nas quais as coisas que são de um modo particular são como elas são porque elas têm que ser como elas são".

Isso não é realmente satisfatório, mas, de um lado, pessoas que não podem ter essa lógica selecionariam outro tópico. Historicamente refletindo, as pessoas são recompensadas pela situação em que muitas diferentes versões podem ser ouvidas, comparadas e checadas por sua plausibilidade ou convincente qualidade (características multiperspectivadas, controversas e pluralistas). Isto é não somente uma frase rasa: as mais importantes questões históricas - como a relação causal entre colonialismo e industrialização - são basicamente e apaixonadamente disputadas.

Aqueles que, de outro lado, rejeitam esse balanço de contradições históricas, devido ao rememorar incerto e ao distanciamento necessário do tempo, poderão também olhar para fora da história. Mas, então, eles não podem entender a presente situação ou eles, falsamente, atribuem isso à "natureza" ou à "lógica". Esta estrutura das explicações retrospectivas e hipotéticas da presente situação de narrações sobre mudanças no passado é a natureza epistemológica da história.

\section{Consequências da "estrutura narrativa" e a "retrospecção a partir de hoje"}

Portanto, o problema do "ensino de História", na época da (pelo menos a quarta fase) globalização e (pelo menos a segunda) era pós-Nacional, não é um cânone de dados para conservar e transmitir para a próxima geração da sociedade e suas subculturas ("população" em vez de uma "nação" mítica como uma comunidade "inventada/imaginada"), mas uma maneira de construir competências de pensar historicamente diferentes contextos (como raça, língua, idade, sexo, religião, cultura, região, classe, poder, riqueza, profissão, consumo, estilo de vida, mentalidade). A "história" tem sido distinguida do "passado". O passado não pode ser restaurado ou reconhecido, mas somente ser reconstruído e contado; portanto, como já dito, uma "narrativa" estruturada é uma inevitável condição da história. 
A história é escrita a partir dos pontos de vista do presente. Isto não pode ser mal compreendido: Uma boa história não pode ser escrita sem uma séria tentativa de pensar partindo das possibilidades e mentalidades das pessoas que viveram no passado. A estrita redução das precondições em que o tempo (sem conhecimento do desenvolvimento posterior e resultados) é uma condição sine qua non do insight histórico. Mas isto é somente um passo necessário, o outro, uma síntese e avaliação do atual ponto de vista é tão importante quanto ("Metodologicamente o historiador tem que andar em duas pernas, na direita a história e na esquerda o presente").

A história é necessariamente e altamente seletiva; $99,99 \%$ de todos os eventos passados, situações e estruturas são esquecidas sem alguma relíquia preservada. Adicionalmente, $99,99 \%$ das informações históricas que estão bem documentadas tiveram que ser deixadas de lado (ainda no caso de estudos muito especializados). Mesmo a história completa de um homem durante um dia, com todas as suas experiências, discursos, ideais e pensamentos, poderia precisar de um longo livro (e.g., James Joyce's, Ulysses). Ademais, tamanhas informações foram possíveis serem preservadas para o futuro (no "estado de arquivo" da história). Mas a "existência funcional" de parte da história dada por uma sociedade ("cultura histórica") é muito menor (o "status de tesouro" da história). (ASSMANN, 1999).

Quais são as condições especiais e necessárias para nosso tempo na história? O que são as tendências que alguém tem que conhecer, detalhadamente, para processos efetivos de orientação em tempos de mudanças e, particularmente, de novas situações no presente e no futuro?

. "Europeização" e "Deseuropeização" (e.g., estrutura "pós-colonial" e/ ou "neocolonial");

. Desigualdades econômicas mundiais e poder mundial;

. Integração europeia;

. Emancipação da mulher;

- Crescente expectativa de vida e transformação das relações entre grupos etários ("acordos geracionais" e "conflitos geracionais");

. Revolução na comunicação (computador, televisão, internet, celular, "base do conhecimento social") e outras supertecnologias;

. Diga-se "globalização" (em harmonia, competição, e conflito);

. Imigração e diversidade ("sociedades multiculturais");

Mobilidade física e mental ("flexibilidade", "aprendizado ao longo da vida");

"Aceleração" de mais desenvolvimentos ("redução do tempo de validade do conhecimento"); 
. Explosão populacional em partes do mundo (e "declínio populacional" em alguns países ricos);

. Poluição ambiental e destruição (mudanças do clima, vida curta das matérias-primas).

Muitos desses fenômenos têm antecedentes em tempos antigos. Tudo a respeito pode ser entendido melhor por meios de comparação e retrospecção. Certamente, às vezes, as situações acima são principalmente produtivas e informativas porque elas mostram maiores diferenças (e.g., mobilidade, relação entre gerações), mas, frequentemente, as similares são também importantes (e.g., "crise ambiental", "sociedades multiculturais").

\section{Versões da "História Geral"}

Ainda: O que é “História Geral?" Esta é a mais decisiva questão. Por muitos séculos, na longa tradição da historiografia, o critério do poder ou dominação foi supremo. De fato, esta foi a origem da própria historiografia. Todo o resto da vida tem sido evidente e enfadonho, portanto, setores mais práticos na sociedade (e.g., relações sexuais, condições ambientais) foram - falsamente - pensados para serem estáveis e a-históricos. Hoje, ao contrário, nós geralmente percebemos como aborrecidos os longos contos sobre determinados governantes ou poderes dominantes, que foram vistos arbitrariamente durante um longo tempo. Mas, ainda hoje, muitos alunos e professores não entendem a maior questão: $\mathrm{O}$ que é "História Geral?". Para eles, a tradição ou identificação política dominante na história continua sem dúvidas.

No entanto, a vida humana é mais velha e mais original do que o Estado. Primeiro o homem e a mulher têm que viver, trabalhar, casar, cooperar e criar seus filhos. Somente depois eles podem organizar e ampliar estados, subjugar e eliminar outros. Portanto, em minha opinião, "antropologia histórica" é certamente "História Geral" (este insight não é realmente novidade; ele era bem conhecido pela escola dos Annales desde 1929). Adicionalmente, a história do dia a dia pode ser aprendida mais facilmente do que aquela dos estados e guerras. Crianças já sabem - ao menos particularmente - o viver diário de hoje. Elas têm um estrelado ponto para trabalhar a partir e para comparações. No caso do estado, lhes falta essa vantagem, porque elas não conhecem ainda o Estado atual.

As pessoas podem saber um conjunto de datas (reinos, batalhas, tratdos, invenções, etc.), sem serem aptas para narrar a história de alguma forma. Isto pode ser visto acontecendo frequentemente, ainda entre estudantes de história 
das universidades. (BORRIES et al., 2004). Adicionalmente, eles podem ser aptos a narrar longas histórias sem criticismo e habilidades metodológicas. Em minha opinião, tais características falham para cumprir uma condição da "competência histórica". Somente a qualificação do pensamento, trabalho, argumentação e julgamento de uma maneira histórica podem ser os objetivos da aprendizagem histórica. A história é interminável e infinita. Isto nunca pode ser aprendido com um "conteúdo".

Embora na maioria dos países - assim como na Alemanha - a maioria dos padrões fixados pelas autoridades é de "padrões de conteúdo", a minoria dos "padrões processuais" é mais importante - e a "oportunidade de aprender padrões", bem como, porque eles estão muito mais próximos às necessidades de estabelecer (e conseguir) "competências".

O problema de um "modelo de competência histórica" - com seções e níveis - e o problema para um "currículo de história" não são idênticos (BORRIES, 2007a) e nem similares (embora ligados um ao outro). Um menino chinês e um menino britânico podem adotar uma equivalente qualificação no "pensar historicamente", se eles somente aprenderem a estudar a história de suas experiências diárias, de suas típicas histórias culturais nacionais, a partir de fontes primárias, como também a partir de novelas históricas e filmes. Mas o conteúdo de suas abordagens históricas - e, portanto, de seus conhecimentos declarados - poderá variar radicalmente.

$\mathrm{O}$ fato de que nós podermos facilmente enumerar alguns tópicos que poderiam ser incluídos na China, bem como na Inglaterra, deveria ser mencionado também. Estes são a "era neolítica (agricultura)", "industrialização", "direitos civis e humanos (invenção e cumprimento), "dependência e/ou mudança das condições do habitat", "outros subcontinentes culturais" (talvez América Latina, para ambos, talvez Índia para o Chinês e China para o Inglês). Mas estas decisões já são concepções normativas. Formalmente, a escolha do conteúdo é mais arbitrária.

Se alguém duvida dessa opinião, ele ou ela tem que assumir as consequências. Então, um professor universitário de História Antiga ou de História Contemporânea não tem competência histórica porque ele não sabe quase nada

3 A Alemanha tem 16 estados membros que são exclusivamente responsáveis pelo sistema educacional e pela manutenção de 2 a 4 tipos de escolas e é completamente impossível analisar os conteúdos canônicos em cerca de 50 comparações curriculares somente de escolas secundárias. A "Associação de professores de história" publicou um tipo de modelo de "padrões de conteúdos em história" em 2006 (VERBAND, 2006), mas, de fato, foi oferecida uma lista de "padrões de conteúdo" sem uma gradação de perfeição (competências) somente. A original "performance de padrões" (ou padrões metodológicos) não foi aplicada em tópicos canônicos: simplesmente as socialmente (nacionalmente) interpretações aceitas foram reproduzidas. 
sobre Cesar ou Mao (para dizer nada sobre Birmânia ou Benin, história de gênero ou ambiental). Eu poderia facilmente mostrar tais lacunas "catastróficas" e furos no conhecimento geral de muitos professores alemães famosos. Em outras palavras: história são dois mundos, um de conteúdo, temas e tópicos; o outro de ferramentas, habilidades, métodos, teorias. Ambos não são completamente independentes: há uma ligação entre eles no mundo das noções, conceitos, estruturas e categorias.

\section{Seletividade e perspectividade num mundo de lealdades e identidades múltiplas}

Narratividade, seletividade e perspectividade talvez sejam as mais importantes características da história e têm que ser discutidas mais diligentemente. Seletividade não é uma deficiência e fraqueza, mas uma condição estrutural sine qua non. Nem organismo, nem mente poderiam relembrar todas as particularidades do passado. Necessariamente, viver é relembrar, bem como é esquecimento. Isto não é só verdade para os indivíduos, mas para a família, a comunidade ou o coletivo. Não obstante, quem está vivendo está rememorando, como também está esquecendo. Relembrança e história deveriam conter conteúdos que são moralmente e intelectualmente honestos. Mas o critério para tal decisão (para estar sóbrio e honesto) é muito difícil, porque - de fato - você tem que omitir $99,99 \%$.

Todos sabem que a história é escrita pelos vitoriosos - ou pelo último dos sobreviventes - pelo interesse dos sobreviventes. Em muitos casos, nós sabemos sobre uma destruição intencional de tradições e documentos dos conquistados (América, China, África). De fato, a informação é pesadamente filtrada pelo ponto de vista dos vencedores. Não obstante, nós frequentemente encontramos uma minoria de documentos ocultos depois da queda dos anteriores vencedores (Como o arquivo Ringelblum da revolta do Gueto de Varsóvia em 1943).

Aparentemente, uma história é escrita ou contada de um ponto de vista de uma comunidade específica e de uma identidade de determinada comunidade, isto é chamado de "concretude da identidade" (veja ASSMANN, 1997, "Identitätskonkretheit" - "concretude da identidade", em German). A segunda guerra púnica foi recontada por Tito Lívio e outros romanos. Foi escrita pelos seguidores gregos de Aníbal também (mas estes livros foram perdidos). Certamente existiram descrições helenísticas de observadores orientais também. 
Uma versão romana e púnica comum não pode ser imaginada, somente um controverso ou dramático debate num tribunal ou em uma etapa.

Mas o que isso significa? Certamente, mentiras são proibidas, mas omissões daqueles "fatos" que são mais importantes para um outro lado ou aspecto são também inadmissíveis. No mínimo, desde o começo da história científica, todas as censuras, todas as objeções, todos os comentários críticos têm que ser considerados e respondidos cuidadosamente. Observações como "eu não estou interessado neste tipo de fontes primárias" ou "tal atribuição da causalidade perturbaria minha interpretação de um modo aterrador" não são mais permitidas. Historiadores devem argumentar, têm que trocar argumentos empíricos, lógicos, teóricos e morais. Portanto, eles têm que estar sempre comprometidos.

De fato, a qualidade da história como "concretude da identidade" (ASSMANN, 1997, "Identitätskonkretheit") produz um dilema para o "pluralismo" (no mundo ou na sociedade) e para estas "características científicas". $\mathrm{O}$ que devemos fazer com a diversidade? Se narrações históricas ganham plausibilidade adicional pela inclusão de outros argumentos e pontos de vista, por métodos científicos perfeitos, elas estão em perigo de perder sua utilidade prática e relevância para a orientação cotidiana de pessoas particulares (específicas) e comunidades. Elas podem perder o poder também para motivar, porque nelas faltam afirmações para o grupo. As "melhores" histórias podem se revelar desconfortáveis. (BORRIES, 2004a) ${ }^{4}$.

O que são comunidades? Certamente, não somente os estados e nações (mais exatamente os "Estados Nacionais" em "Nações-Estado"). Isto é um conceito ideológico muito tardio - embora bem-sucedido (ANDERSON, 1983; GELLNER, 1983; HROCH, 2005), que, contudo, nunca fornece soluções para muitos dos problemas do mundo. De uma história inteira da historiografia, nós sabemos que cidades, clãs, famílias, conventos, comunidades religiosas, dinastias, minorias, classes e subcontinentes culturais têm suas próprias histórias e historiadores. Nós poderíamos, artificialmente, decidir tomar decisões normativas, não em um autoevidente ("natural") ato. Para dizer a verdade, isto seria uma decisão muito má, porque isto poderia dar às pessoas mais uma identidade, e não um par ou um conjunto compatível delas (para diferentes situações e relações).

4 Outro risco ocorre também: é "história" arbitrária, se nós seguirmos o modelo descrito? É "história" de algum uso, se nós aceitarmos sua complexidade e ambiguidade, como mencionado? E sobre as limitações e tolerâncias? Nós temos que seguir as célebres palavras de Voltaire, podemos rejeitar completamente a opinião de um colega, mas defendemos firmemente o direito deste homem expressar a sua opinião? O caso é muito complicado: A pré-condição é que os oponentes aceitem o mínimo de "racionalidade", "não agressão" e "discurso mútuo" com o objetivo de uma "aceitação parcial". Se isto não ocorrer, o sistema não trabalha. Este problema precisa ser trabalhado em detalhes. 
Todas essas redefinições já são conceitos centrais dos padrões processuais de aprendizagem histórica. Como já foi dito, o acesso metodológico é tão importante quanto um conteúdo padrão ou uma abordagem temática. Saber sobre a seletividade, perspectividade, caráter hipotético e narratividade da história. E isto de um modo muito concreto, com respeito a exemplos particulares - isso é mais importante do que saber dados sem reflexão, dogmáticos e tendenciosos sobre o Império Romano, a Revolução Francesa, a Reforma Alemã ou a Industrialização da Inglaterra.

Não podemos esquecer que todas as escolhas "canônicas" são muito complicadas e basicamente controversas. Os assim chamados "fatos", a "narrativa", a síntese e as consequências atuais ("mensagens") não podem ser deduzidos a partir de um modo lógico e não ambíguo. Eles são interdependentes e constitutivos de cada um de maneira espiral. Em uma sociedade democrática e pluralista não há direito e autoridade de prescrever uma certa interpretação para todos os cidadãos ou todos os estudantes. (BERGMANN, 1975). Observe o caso da Revolução Francesa. O que a faz significante para hoje: democracia ou ditadura, direitos humanos e civis ou capitalismo, liberalismo ou terror totalitário, guerra civil e externa ou abolição da escravatura, sociedade burguesa ou sociedade civil (cidadania), secularização ou construção nacional?

\section{Dupla meta: conteúdos motivadores e métodos transmissíveis}

Isso praticamente demanda duas metas em todas as unidades curriculares ou conceitos: um método e um conteúdo orientador único. A orientação metodológica passaria por três estágios: Desenvolvimento de habilidades de trabalho; manuseio de material, características; e epistemologia da história; nas escolas, isto se configura como um elevado risco de ruptura para o primeiro ou ainda mais o segundo nível. O que precisamos é da "gramática" metodológica da temática em si. Com certeza, isso pode ser feito em estudos, somente a partir da mobilização de tópicos particulares:

. A análise histórica e historiográfica de um filme (e.g. "The homesickness de Walerjan Wrobel" ou "O retorno de Martin Guerre");

- Conquista espanhola nas Américas Central e do Sul - Com o foco na discussão e mudança de perspectiva da escrita histórica dos vencedores para a história dos povos derrotados (BORRIES, 2001, p. 148-161);

- Produção e escrita de uma história particular que faça sentido (e.g. sobre a perseguição às bruxas na era moderna); 
. Questionar: "Existe uma inter-relação causal entre 'colonialismo' e 'industrialização' (i.e. descrevendo e decidindo uma controvérsia)?”.

Para adentrar mais detalhadamente gostaria de requerer o desenvolvimento de um modelo de competência estrutural e de niveis de competência. (KÖRBER; SCHREIBER; SCHÖNER, 2007; SCHREIBER; KÖRBER, 2006). Isso não pode derivar da política ou da filosofia, mas da epistemologia da história (em outras palavras, a lógica da historiografia). O pensamento histórico significa fazer sentido fora do tempo, da mudança e da experiência da crise. Isto não é um estágio final que é somente alcançado por professores universitários, mas tem que ter lugar desde o início. Caso contrário, sem conexão com a identidade e "Lebenswelt" (mundo diário), o assunto "história" seria inútil. Isso traz a questão da iniciação para aprendizes.

- O modelo "Fuer Geschichtsbewusstsein" (para a consciência histórica) (SCHREIBER; KÖRBER, 2006; KÖRBER; SCHREIBER; SCHÖRNER, 2007) distingue quatro áreas de competência: "competência histórica em fazer perguntas", "competência histórica metodológica", "competência histórica de orientação", "competência histórica de noções e estruturas". Três dessas descrevem os (repetitivos) processos de pensar historicamente, o quarto significa um estoque de conceitos e categorias que são usadas e cumulativamente melhoradas por novos processos;

- Em outro aspecto, o modelo tem cinco níveis: todas as fases de competência iniciam-se em um nível "básico" de um caráter "não convencional". O terceiro nível - "intermediariamente" - é chamado "convencional", o quinto - "elaborado" - é indicado pelo "transconvencional" pensamento. No meio, as lacunas são preenchidas se "agarrando à convenção" e ao "criticismo da convenção";

- Com certeza, cada modelo não é a "realidade", mas uma construção em si mesmo. Isto é, somente uma tentativa de estruturação que pode revelar-se mais ou menos elegante do que outra. A questão é, se outros modelos podem ser facilmente e frutuosamente explicados e traduzidos para este modelo;

- Comparavelmente "fácil" e acessível processo de mudança e exemplos de diferenças existentes em alguns campos:

. Família, vizinhança e a cidade durante as últimas três (ou quatro) gerações;

"Índios vermelhos" ("nativos americanos");

Mídia e "revolução das comunicações";

Viagens e mobilidade, comidas e bebidas típicas;

. Relações entre gerações; 
. "A maravilha que era a Índia";

- Outro tipo de processo é muito mais complicado: Revoluções compreensíveis da vida social como um todo ("avanços evolutivos") podem ser entendidos a partir de:

. Desenvolvimento do "homo sapiens" (hominização);

- Advento da sociedade agrária (Revolução Neolítica);

. Primeiras civilizações (estado, cidade, escrita, hierarquia, guerra);

. Racionalidade e redenção religiosas (Jaspers' (1983) "Axis Era");

. Europeização (especialmente desde Colombo, 1492 e Da Gama, 1498);

. Industrialização (e.g., Desde a melhoria da máquina a vapor por Watt em 1769, mas não por causa dela);

. Guerras mundiais e mortalidade em massa;

. A assim chamada "globalização".

De fato, isto já está há muito tempo em uma lista. Assim, as propostas não podem ser impostas de um modo autoritário, mas somente oferecidas para discussão e estudo. O primeiro princípio da didática da história define: "Ouse usar sua própria razão" (Immanuel Kant) e o segundo é: "Para primeiramente tratar-se de forma diferente e em segundo tratar como suspeito" (Wilhelm Busch).

\section{Monoperspectividade ou como tornar absoluta a sua própria proposição}

Certamente, todos podem identificar a verdade com suas próprias perspectivas: "Este sou eu, é minha visão, é meu interesse, é minha verdade". Isso é sempre feito, todos os dias, na vida e também nas lições de história. Em muitos casos, isso realmente não faz mal a ninguém e é uma contribuição para sentir-se melhor. Isso economiza energia, pensamento e emoções negativas. Em outros casos, isso pode conduzir a catástrofes sociais. Se um casal sabe muito bem que sua posição é a única correta, se eles não estão mais aptos para perceber e para refletir outros interesses e argumentos, o divórcio virá em breve.

O mesmo é verdade para coletividades e sua história, por exemplo, nações ou comunidades religiosas. A força da autoconfidência frequentemente perverte-se em uma fraqueza de mau entendimento do mundo e da situação. Assim, uma pessoa ou um grupo com uma reivindicação de absoluta validade a partir de seus próprios pontos de vista ("monoperspectividade", "representação única", "infalibilidade") não somente danifica seus próprios interesses e posições, mas também põe em perigo a paz. Sob as condições tecnológicas da atualidade, isso 
é um problema sério: "Se todos se sentam em um único barco que pode ser virado por cada um deles, a história de todos e de todas as relações de parceria torna-se o destino de todos".

Não obstante, esta solução é vista como normal nas lições de história em todo o mundo. Especialmente, o realizar absoluto das perspectivas nacionais é constituído inconscientemente e imperceptivelmente (se não agrada e esclarece). Indiscutivelmente e inquestionavelmente, seleções normalmente automáticas incluem monoperspectividade. Normalmente, a educação de professores é muito restrita para que sejam conscientes desse automatismo - e os estudantes nunca aprendem que existem outras versões respeitáveis da história.

\section{Três tipos de conhecimento?}

A distinção de conhecimentos não sistemáticos, conhecimentos canônicos, referenciais do conhecimento e uma concentração no problema dos quadros de referência do conhecimento tem sido um conjunto de propostas originais deste texto e pode ser frutífera. Primeiramente, nós temos que relembrar que a aquisição de conhecimento canônico no ensino de História na escola nunca foi trabalhada, não ainda para uma pequena minoria ou elite. Na Alemanha, alguns trabalhos empíricos foram feitos antes de 1968 entre aqueles $10 \%$ das pessoas que já fizeram seus exames finais nas escolas e que se preparavam para estudar nas universidades. (BORRIES, 1988, p. 186; BORRIES, 2004b, p. 138). Naquele tempo, eles tinham aprendido "história" em um sistema cronológico duas vezes (primeiramente por cinco e depois por três anos). Os resultados foram muito desapontadores. Uma visão global do conhecimento histórico é uma ilusão, embora uma generalização. Isso é teoricamente impossível também, porque nós não precisamos de uma "visão global", mas várias delas (uma feminista, uma liberal, uma socialista, uma ecológica, etc., versões da história global) e uma comparação crítica entre elas.

A ideia de um "referencial de conhecimento" é muito mais interessante. Não obstante, é muito mais infectada e determinada por uma escolha especial, um especial interesse e uma perspectiva especial como um outro tipo de interpretação e um plano maior de narrativa, que é inevitável. Isso leva a uma decisão necessária:

a) Ou nos ater a um particular, bem definido - principalmente, na maior parte "nacional" -, uma identidade que nós tentamos fortalecer tão intensamente e efetivamente quanto possível. Então nós tempos que 
enfrentar a censura de manipular e doutrinar nossos estudantes, de recursar as contribuições das identidades de minorias, imigrantes, opositores, garotas e assim por diante. Obviamente, o fazer de uma nova, mas transnacional (ex. "Europeia") identidade ("construção mental da Europa"), uma outra versão de alguns tipos de intentos, algumas estruturas lógicas;

b) Ou nós pretendemos uma capacidade de pessoas novas atuarem, brincarem e agirem em uma multidão de diferentes identidades (diferentes unidades nacionais, diferentes unidades sociais, diferenças culturais ou sexualidade, etc.), que podem ser escolhidas e combinadas livremente por indivíduos autônomos (com responsabilidade intelectual e moral). Neste caso, nós necessitamos confrontar a objeção de que nós estamos negligenciando uma orientação social fixa e psíquica de nossos filhos.

Para mim, a decisão é clara. Por 200 anos, a "história" foi a mais poderosa ferramenta para danificar e utilizar mal as crianças para propostas de "classes políticas", para "decisões de minorias" neste trabalho. Entretanto, eu tenho que contribuir para uma alternativa que eu sei que é muito arriscada e desconfortável. Talvez improvável e impopular. Talvez a natureza humana - ao menos das pessoas jovens - não é realmente preparada para manipular a história de uma maneira multiperspectivada, controversa e pluralista.

Deixe-me expressar isso de outra maneira. No passado, a visão da aprendizagem histórica foi alterada frequentemente, de acordo com a mudança no sistema político (ex., na Alemanha em 1870/71, 1918/19, 1945/49, 1968/69, 1989/90). Mas a lógica do comportamento futuro desejado para os jovens não foi mudada: fornecimento de lealdade para com o poder através de doutrinação, preparação para sacrificar-se em relação aos outros. Somente alguns sinais de trânsito são mudados, não o ato em si de trafegar a rodovia. A história seguiu produzindo "alienação". Interpretações frequentemente mudadas, o conteúdo

5 Na noção de "memória cultural" a compreensão de "cultura" é um problema. Parece que uma velha versão de "alta cultura" é incluída, a cultura é o domínio das elites. Isto é bastante surpreendente, desde a noção de "cultura de massa" ou de "cultura como práticas simbólicas" prevalece e recoloca mais e mais o uso normativo de "cultura" como uma característica da educação do povo. A versão de J. Assmann (1997) tende mais ou menos para ser típica para sociedades pré-democráticas. Hoje, nós não acreditamos em uma cultura fixa e uniforme na sociedade, mas nós percebemos uma quantidade de mutantes e variadas subculturas (regiões, classes, gênero, minorias, grupos de idade, profissionais, etc.) com infindáveis misturas e transições. Mas isso torna necessária e questionável uma decisão central acerca da "história" na escola (como "memória cultural" e "transferência cultural”); isso pode levar a uma ação não democrática e ilegítima. 
normalmente se mantendo, faltando a capacidade de refletir sobre as próprias decisões. Em vez disso, a lógica, a figura do próprio pensamento tem que ser substituída e renovada.

Isso não pode ser mal entendido. Se a contribuição da história para a identidade não é ligada à "nação", "nacionalidade" e "Estado-nacional" somente, o efeito da história multiperspectivada, controversa e pluralista não se relaciona somente à nação. Estes meios:

a) A lealdade para com uma "comunidade imaginada", que é chamada "nação", é uma questão importante para indivíduos. Mas, muitas pessoas têm boas razões para serem leais a duas nações ou a nenhuma nação. E muitas definições de conflitos "nacionais" uns com os outros demandam lealdades incompatíveis. Nós somos responsáveis pela autonomia em casos de crise e também em conflitos;

b) Para dar um único exemplo: ensinar uma história que pode ser entendida e discutida (não completamente aceita) por Sérvios Ortodoxos, Católicos Croatas e Bósnios Muçulmanos, ao mesmo tempo, é uma meta muito importante, mas não a única;

c) Uma vez que cada um tem um bem social, um bem (sub) cultural, um religioso, um sexual, um geracional, uma identidade linguística e um ponto de vista nacional também, a história é ligada a todos estes setores da vida. Para mim, a história da infância é tão importante para a vida futura das crianças - por exemplo, sua forma de conduzir e direcionar seus filhos - como é a nação holandesa. O mesmo é verdade para a história ambiental, história econômica e assim por diante. A identificação exclusiva de "politics, policy and polity" com "história" é tão prejudicial e deficiente como aquela da "nação";

d) "História" é um modo de pensamento, um acesso ao mundo e a si mesmo. Portanto pode ser aplicado e transferido para todas as partes e seções da vida. Isso tem uma consciência crucial para o ensino de História. Significa que o "pensamento histórico" é aprendido não somente com temas gerais da "história", mas também em cursos de língua e literatura, ou na religião também (se estes tópicos são somente feitos de uma forma inteligível). Muitos indivíduos lembrarão que suas realidades historicamente relevantes foram aprendidas e introduzidas por um dramaturgo, um museu ou uma cidade, não por professores de história;

e) Muitas pessoas deveriam dizer: "Sim, história é muito complicada, mas nós tempos que simplificá-la por razões pedagógicas. E isso significa usar a história nacional como um sistema canônico e referencial de conhecimento, pelo menos para uma pessoa comum e para novatos". 
Isto precisa claramente ser rejeitado, porque significa discriminação para com "outra" criança, grupos minoritários de imigrantes, classes baixas, garotas e assim por diante, com seus interesses menores em violência e guerra... A direção dessa simplificação seria um ato injusto e ideológico por si mesmo.

Finalmente, uma redefinição muito importante é necessária aqui: multiperspectividade é uma perspectiva também. É logicamente impossível escapar do problema da seleção e dos pontos de vista. Não obstante, uma designação aberta e a discussão dos dilemas possibilitam uma solução parcial. Embora essa visão seja especialmente difícil para iniciantes, isso pode ser exercitado de forma frutífera com seleções menos extremas e é somente raramente mencionado em livros de história e lições. Assim, consciente e explicitamente, multiperspectividade é uma perspectiva, mas pode trazer uma meta perspectiva o tempo todo.

\section{Quatro estratégias para a seleção de tópicos históricos em sociedades de imigrantes}

Os processos do pluralismo e as demandas por autonomia individual em uma sociedade democrática são a razão mais importante contra a tradição central do "currículo por conteúdos". Em sociedades pluralistas, a orientação via história é diferente entre os cidadãos (e "não naturalizados convidados" também). Meninos e meninas, heterossexuais ou homossexuais, alemães do leste e do oeste, passam por diferentes processos de identidade. A lista poderia facilmente continuar. Mas a situação entre a maioria dos "alemães completos" (de pai e mãe) e crianças com ascendência imigrante (pelo menos de um lado) é a meta principal. Sobre $25 \%$ - muitos deles muçulmanos - mostram uma origem imigrante e eles evidentemente têm uma "consciência histórica" diferente. (BORRIES et al., 1999, p. 292)6. A Alemanha é um "país de imigrantes"; e seu ensino de História tem que refletir sobre o fato (mas até agora não o faz, normalmente).

Alguns anos atrás, quatro modelos foram distinguidos para resolver o problema, o que teve suas vantagens e seus fracassos, que podem ser combina-

6 Um problema adicional não pode ser esquecido completamente. Houve uma grande migração da Alemanha do Leste (DDR) para a Alemanha Oeste, principalmente antes de 1968 e desde 1989. Este movimento interno continua e é algumas vezes relacionado também a crises de identidade. 
dos em diferentes misturas e estruturas. (BORRIES, 2004b; BORRIES et al., 2004, p. 428):

a) "História nacional como uma entrada para a naturalização": o acesso tradicional seria fazer da grande narrativa mítica nacional uma condição de naturalização e integração; e de fato as primeiras tentativas são feitas para testar, não somente as habilidades na língua alemã, mas também - mais elementar - questões históricas, que não podem ser respondidas pela maioria dos alemães. Alternativas mais inteligentes e funcionais podem ser inventadas também, por exemplo, a versão "construtivista" do processo de formação nacional, desde o século dezoito até a primeira parte do século vinte, incluindo o caminho alemão para catástrofes em 1914/18 e 1933/45. Esta solução não pode ser negada antecipadamente, porque claramente a Alemanha precisa de um novo tipo de "repetição da construção nacional" (trazendo juntos imigrantes, alemães Orientais e Ocidentais) a partir de uma alteração séria para assegurar a paz, a integração europeia e a cooperação internacional;

b) "História dos direitos humanos como religião civil": Nem uma religião comum, nem uma tradição ideológica nacional podem servir como um instrumento simples de coerência ("cimento") para a sociedade germânica. Lealdade com os "direitos humanos e civis", para uma "lei democrática fundamental", é uma alternativa. Isso foi também chamado de "patriotismo para com a constituição". Mas isso é abstrato (e a forma abstrata de "direitos humanos e civis" é evidentemente um tópico chato para pessoas jovens). Se o processo de construir, se a evolução, primeiro levar a cabo os "princípios democráticos" e os "direitos humanos" forem investigados em "casos históricos" detalhados sobre pessoas concretas, isto é uma boa introdução. Isso inclui também que os processos não são completos (e.g., "direito de preservação natural", "direito de autenticidade cultural"), mas abertos para o futuro e abertos às contribuições de outras regiões (não europeias) (RÜSEN, 1994);

c) "História de 'life-world' e experiências de imigração como apoio para orientação": Como já foi mencionado, muitas crianças nunca compreendem que história tem algo a ver com eles ou com suas vidas. Isso é especialmente o caso de grupos não privilegiados como os deficientes, garotas e imigrantes. A situação pode ser mudada se as experiências de pessoas em situações similares ou com histórias familiares similares forem contempladas. Certamente, isto é impossível de se contemplar na história de todas "nações" (ou "culturas"), a partir das quais as crianças imigrantes veem (ou se influenciam). Mesmo a inclusão de duas mais frequentes unidades (na Alemanha isso significa Rússia e 
Turquia) é difícil conseguir. Uma concentração de condições particulares de migração em si mesmo (o desenvolvimento através de algumas gerações) parece ser a melhor ajuda para o entendimento e a integração em ambos os lados, majoritários e minoritários;

d) "História das mentalidades como extensão das identidades": A definição de identidades individuais e coletivas mudou muito em processos longos e curtos. Homens e mulheres não são mais o que eles fizeram nos séculos dezessete e dezenove. Pessoas jovens e velhas desenvolvem seus sentimentos e suas relações também. "Nações" ("estados nacionais" em "nações-estado") foram constituídas tardiamente nos séculos dezoito e dezenove e começaram a transformar suas concepções e estruturas no final do século dezenove e início do século vinte. Estudar seus desenvolvimentos pode ser uma grande ajuda em decisões individuais e experiências. Isso remove aqueles processos pessoais do reino da "natureza" ou da "determinação", trazendo-os, então, para um campo de "contingencialidade" e "escopos para decisões". Talvez os casos aprendidos sejam mentalmente difíceis (mesmo sobrecargas) para alguns estudantes (ou mais culturas tradicionais), mas é necessário oferecer isto a eles.

Isso não pode ser descrito e discutido mais detalhadamente. Mas uma das consequências é que conteúdos "mais suaves" e "mais difíceis" não podem ser organizados ao longo de uma simples e única linha cronológica. Outros princípios de sequências e outras estruturas de conhecimento têm que ser levados em consideração também. (BORRIES, 1995, 2001, 2004c; BORRIES et al., 1999).

\section{Em direção a um núcleo curricular de orientação metodológica}

Qual é a condição? A continuidade de propostas para um debate trata-se de uma apropriação muito pessoal, depois de longas considerações e muitos experimentos - principalmente com estudos universitários - também (veja BORRIES et al., 2004). As sugestões estão especificamente concentradas no início e no final do tema central "História" na escola. A lista não é por meios consensuais do debate alemão ou pela reprodução de tendências curriculares nos 16 estados membros da Alemanha para seus diferentes níveis e tipos de escolas. Isso seria uma tarefa muito difícil e exaustiva, com muitas pequenas pesquisas prévias (veja HANDRO; SCHÖNEMANN, 2004; JEISMANN; 
SCHÖNEMANN, 1989). Então eu tenho que reduzir minha proposta às minhas convicções pessoais. (BORRIES, 1995, 2001).

a) Estudantes têm que aprender, a partir de muito cedo, que história é uma reconstrução hipotética, um ato mental de construção de sentido e uma narrativa retrospectiva. Isso é mais fácil no estreito campo do dia a dia e da experiência histórica. A história inicialmente ensinada deveria, portanto, investigar a história local e familiar das últimas três ou quatro gerações, o que tem a grande vantagem de utilizar "memórias comunicativas" (veja ASSMANN, 1997). Em toda parte, as acelerações extremas têm colocado pessoas jovens em um mundo que é completamente diferente da infância de seus avôs. Frequentemente, o centro da cidade, a cidade ou o bairro foram profundamente modificados durante os últimos 50 anos, por exemplo, de uma economia agrária para uma industrial e de serviços. Em tais processos de pesquisa, estudantes podem obter o insight de que eles estão envolvidos na história, que seus avôs e avós não somente viveram na história, mas influenciaram a história. Depois do ensino convencional da história, nós frequentemente achamos que a história vai se completando no pensamento como um todo, "um país estrangeiro", sem conexão com a realidade e a vida presente ("alienação mental");

b) Mas nós não podemos esquecer a cronologia e a data dos eventos, processos e estruturas. Com crianças mais novas isso deveria ser feito a partir da organização de pinturas (pirâmides, catedrais, arados, máquinas, roupas, armas, pessoas trabalhando, invenções, etc.). Certamente, uma linha do tempo ilustrada (na Alemanha "Zeitstrahl" ou "Geschichtsfries") é o produto óbvio (e uma versão impressa pode ser adicionada e comparada a uma autofabricação). Isso é muito importante porque muitos diferentes fenômenos ocorreram ao mesmo tempo (diferentes setores, regiões, continentes, atores). A história não é de nenhuma maneira um "processo de tópicos". Certamente, este método é adaptado à curiosidade, o hábito de coletar coisas e a "fome" por imagens da infância tardia, sua preparação para aventuras, descobertas e invenções. Certa habilidade para estabilizar ordens cronológicas para todo trabalho futuro - deveria ser o resultado (frequentemente não alcançado na cronologia ensinada tradicionalmente). Em alguns aspectos, isso vai ser mais um exemplo de história "antropológica" do que "política";

c) Talvez um ano depois, um processo similar de insight pode ser repetido adicionalmente, principalmente pretendendo representar e descrever as partes do mundo e a história fora da Europa com imagens motivadoras 
(prédios, ferramentas, esculturas, pinturas, roupas, peças de mobiliário da China, Índia, pré-islamismo e islamismo, Japão/Coreia, Indochina/ Indonésia, Sibéria e Ásia Central, mas África negra e América pré-colombiana também). Textos muito curtos (poemas ou aforismos) podem ser adicionados. A censura dessas transmissões muito convencionais - até estereotipadas e prejudiciais - impressões do "exótico", cultura "oriental" com "canibalismo" e "nobres" barbáries é possível, tem que ser aceita e parcialmente levada em conta. Isso é possível para investigar a "mensagem" e o "julgamento" em algumas dessas representações da "ordem", "o estrangeiro". O caráter "projetivo" e a comparação oculta em nossos próprios desejos e medos podem ser revelados em simples e pequenos exemplos. Geralmente, isto é mais importante ser feito na história dos "outros" fora da Europa (e seus descendentes, os Estados Unidos) no mínimo presente e visíveis desde muito cedo; eles são cerca de $90 \%$ da população mundial. Certamente, diferenciações e pesquisas críticas de problemas selecionados têm que ser seguidas em idades mais avançadas;

d) Outra necessidade tem que ser conhecida muito cedo: as radicais mudanças e um desenvolvimento em setores da vida ao longo dos tempos (contínuos) e os processos de aceleração nos últimos séculos. Novamente, isso deveria estar longe e demasiado complicado - ou somente necessário - nesse fenômeno. Nós temos que selecionar um ou dois (e a seleção pode ser diferente entre professores): alguns podem preferir "comunicação e mídia", outros "mobilidade, transporte e trânsito", outros "população e expectativa de vida", um quarto grupo "conhecimento de física e química" ou "perfeição técnica e efeitos destrutivos das armas" ou "eficácia da produção e utilização da energia". Certamente, esses são dois grandes riscos, a "ilusão do progresso" e o isolamento de setores demonstrados a partir de outros a ele relacionados. Ainda, muito tem que ser resistido (e parcialmente lutar). Pelo menos entre o "menor grau das crianças", o perigo de nunca se perceber o outro lado das formas de vidas passadas é mais sério do que aqueles mencionados. Adicionalmente, a ambivalência de muitas invenções (armas, efeitos negativos no meio ambiente, desperdício de matéria viva, perda de equilíbrio e concentração) deveria ser levada em conta;

7 Quando se analisa "seções longitudinais" ou se faz "estudos longitudinais" em história, não é fácil seguir a versão de MacNeill (1963) - The Rise of the West. Mas, pelo menos, é possível levar em conta outras versões e mencionar Lévi-Strauss (1972) - Race and History, com suas observações sobre o invisível e o irreconhecível empreendimento "para o outro". 
e) Estes são alguns - embora raros - "conteúdos históricos" ou "fenômenos históricos" que são compulsoriamente aprendidos por alguns, pelo menos na Alemanha, "desde o início do primeiro século vinte". Certamente, "Ditadura Nazista, Guerra Nazista e Crimes Nazistas" são alguns deles. Razões de "história cultural", de ética para política, de relações internacionais e mais alguns, podem ser enumerados. O Nacional Socialismo é de fato frequentemente coberto em outros assuntos maiores, mas isso não deveria ser tratado tarde demais em "história", o que significa que ele deve ser tratado de forma sistemática e reflexiva. Isso é essencial para garantir que, desde cedo, todas as crianças não terão já assumido e fixado posição em direção ao Nacional Socialismo, por exemplo, fora da família ou amigos ou na mídia, antes os tópicos são trabalhados através - para se dizer "cientificamente" - da escola. Isso é mais importante, por existir um conflito sério entre o Nacional Socialismo e a "memória comunicativa" e a "transferência cultural". (WELZER et al., 1997, 2002). De modo que, é um argumento forte contra uma simples cronologia estruturada por professores de história (BORRIES, 1995);

f) Ao menos um segundo conteúdo histórico obrigatório tem que ser mencionado e nomeado: "industrialização". Isto não significa um fenômeno isolado na Inglaterra no final do século dezoito, mas o longo período, contínuo, acelerado e o processo mundial abrangente em novas regiões do mundo, novos setores da vida, novas tecnologias de produção, novos saldos e assimetrias entre países, em um complexo ritmo temporal de mais de 200 anos. A vida de todos - garotas ou garotos, nativos ou imigrantes, ricos ou pobres - será fortemente influenciada pelos estágios passados desse processo como também pelo recente e pelo futuro;

g) A habilidade, não apenas para entender, mas também para contar história, tem que ser demonstrada e exercitada explicitamente. $\mathrm{Na}$ Alemanha, isso é certamente uma tradição do "aprendendo história pela pesquisa histórica” (DITTMER; SIEGFRIED, 2005; MEBUS; SCHREIBER, 2005). Um acesso muito modesto tem sido a "orientação através de fontes primárias" desde os anos 1970. Mas a noção de "fontes primárias" e as técnicas de verificação e o exame material ou a informação para sua validade e utilização têm que ser ensinados e mostrados diretamente. $\mathrm{O}$ erro tem frequentemente sido a seleção de somente um bom e sólido material. Assim, a tarefa que resta é apenas extrair suas informações importantes. Nós sabemos isso a partir de estudos empíricos (BORRIES et al., 2005; BORRIES et al., 
1995); desafortunadamente, os passos nesse pensamento permanecem frequentemente esquecidos ou são considerados superficialmente. Portanto, aos estudantes deveria ser dado um material cru real (em parte válido, mas em parte duvidoso) para estudar isso e produzir uma tomada de posição dos fenômenos da história. A seleção pode incluir fontes primárias (textos e pinturas) de diferentes lados, teorias, pesquisas científicas, relatos populares e textos ficcionais (histórias curtas, novelas, romances, filmes, etc.). O tópico deveria ser importante, móvel e motivador, como "Perseguição às Bruxas no início da era moderna", "Peste Negra' na Europa desde 1347", "Emigração alemã para os Estados Unidos e Imigração Alemã nos Estados Unidos" ou "A Guerra Civil na Espanha 1936-1939". Alguns desses exemplos já têm sido testados: resultados surpreendentes é que mais pupilos - e mais estudantes - têm enormes dificuldades em produzirem suas próprias narrativas históricas plausíveis - a despeito de um modelo duradouro de "orientação por fontes primárias" nas escolas alemãs;

h) A história usualmente não é produzida por cidadãos em si mesmos a partir de fontes primárias (isto não é ainda verdade no caso de historiadores universitários). O uso normal da história é ouvido ou visto por pré-fabricada, pronta e perfeita narrativa histórica, por pessoas, jornais, filmes, TV, livros, especialista, guias de turismo. Isso foi um grande erro da história alemã, ensinada desde 1970, que confiou totalmente em uma "base de fontes primárias" em vez de "métodos gerais de orientação" ou "promoção de competências". Como exercitar a habilidade de análise pré-determinada de historiadores em vez de produzir suas próprias histórias (nós chamamos isto de "Desconstrução" em vez de "Reconstrução". (KÖRBER; SCHREIBER; SCHÖNER, 2007; SCHREIBER; KÖRBER, 2006). A melhor forma é uma abordagem comparativa:

Analisar três livros de bolso sobre o "Regime Nazista" (ou a "Revolução Francesa", ou a "Conquista Espanhola da América" ou a "Reforma Alemã")! Examinar a mensagem transmitida (consequências implícitas e explícitas para hoje e amanhã), a sintética e contextual narração com suas teorias nas entrelinhas, os fatos mencionados e substanciais - os fatos omitidos e negados - e as relações entre essas três camadas da história!

(Certamente, isso é uma tarefa muito dispendiosa, que tem que ser preparada por anos, etapa por etapa. O processo de análise é um bocado mais fácil, se os três relatos são claramente escritos em diferentes épocas ou décadas). 


\section{REFERÊNCIAS}

ANDERSON, B. Imagined communnities: Reflections on the origin and sprend of nationalism. London: Verso, 1983.

ASSMANN, J. Das Kulturelle Gedächtnis. Schrift, Erinnerung und politische Identität in frühen Hochkulturen (Cultural memory: Writing, memory and political identity in ancient civilizations). Müchen, Germany: Beck, 1997.

ASSMANN, J. Erinnerungsrãume. Formen und Wandlungen des kulturellen Gedächtnisses (Spaces of memory: Forms and changes in cultural memory). München, Germany: Beck, 1999.

BERGMANN, K. Geschichtsunterricht und Identität. Aus Politik und Zeitgeschichte (Teaching history and identity: Politics and contemporary history). Supplement to "Parlament", v. 39, p. 19-25, 1975.

BORRIES, B. von. Geschichtslernen und Geschichtshewnstein. Emprische Erkundungen zu Erwerb und Gebrauch von Historie (Lerning history and historical consciousness: Empirical research into acquiring and using history). Stuttgart, Germany: Klett, 1988.

BORRIES, B. von. Inhalte oder Kategorien? Überlegungen zur kind, sachzeit und shculgerechten Themenauswahl für den Geschichtsunterricht (Contents or categories? Reflections on the selection of themes for history teaching, doing justice to child, subject matter, time and school.) Geschicte in Wissenschaft und Unterricht, v. 46, p. 421-435, 1995.

BORRIES, B. von. Überlegungen zu einem doppelten - und fragmetarischen. Durchgang im Geschichtsunterricht der Sekundarstule (Reflections on a double - and fragmentary - cycle of history in secondary education). Geschichte in Wissenschaft un Unterricht, v. 52, p. 76-90, 2001.

BORRIES, B. von. Belastende Geschichte - Erinnerung, Erforschung, Verarbeitung, in Flucht, Vernichtung un Vertreibung in der Euroregion Neisse-Nisa-Nysa. Wo Kommen sie her? Wo sind sie geblieben? (The burdens of history, Memory, research and coming to terms with destruction,flight and expulsion in the Ruro-region of Neisse-Nisa-Nysa. Where do they come from? Where have they gone?). Deutsch-tschechisches Forum der Franen. Dokumentation, Berlin: private undated edition, n. 5, p. 226-236, 2004a.

BORRIES, B. von. Lebendiges Geschichtslernen. Bausteine zu Theorie und Pragmatik, Empirie und Normfrage (Lively learning of history: Contributions to theory and practice, empirical and normative problems.). Schwalbacj/TS., Germany: Wochenschau, 2004b.

BORRIES, B. von. Warum ist Geschichtslernen so schwierig? Neue Problem felderder Geschichtsdidaktik (Why learning history is so difficult? New problems in history didactics. In: BEHRENS, H.; WAGNER, A. (Ed.). Deutsche Teilung, Repression und Alltagsleben. Erimnerungsorte der DDR-Geschichte. Leipzig, Germany: Forum Verlag, 2004c. p. 69-96, 284-288. 
BORRIES, B. von. So sahen sie ihre "Entdecker". - So sehen sie ihre "Entdekker"! Übungsmaterial zum Perspektivenwechsel (am Beispiel Lateinamerika). (like this they saw their discoverers - Like this they see their discoverers! Exercises in perspective change (with Latin America as an example). In Durchbrüche von Wirtschaft un Wissenschaft - Krisen von Unswelt und Innenwelt? Versäumte Lektionen zur Ökologie und Metalitätsgeschichte. Herbolzheim: Centaurus, 2007a.

BORRIES, B. von. Kompetenzmodell und Kerncurriculum (Model of competences and core curriculum. In: KÖRBER, A.; SCHREIBER, W.; SCHÖNER, A. (Ed.). Kompetenzen historischen Kenkens. Ein Strukturmoell als Beitrag zur Kompetenzorientiernung in der Geschichtsdidaktic. Neuried, Germany: Ars Una, 2007b. p. 334-360.

BORRIES, B. von; FILSER, K.; PANDEL, H. J.; SCHÖNEMANN, B. Kerncurriculum Geschichte in der gymnasialen Oberstufe (Core curriculum history in the senior stage of the gymnasium.) In: TENORTH, H. E. (Ed.). Kerncurriculum Oberstufe, Biologie, Chemie, Physik, Geschichte, Politik. Weinheim and Basel, Germany: Beltz, 2004. v. 2, p. 236-321.

BORRIES, B. von; FISCHER, C.; LEUTNER-RAMME, S.; MEYER-HAMME, J. Schulbuchvertäbdwusm richtlinienbenntzung und Reflexionsprozesse in Geschichtsunterricht. Eine qualitative-quantitative Shüler und Lehrerbefragung im Deutschsprachigen Bildungswesen 2002 (Understanging of textbooks, use of guidelines and processes of reflection in teaching history. A qualitative-quantitative enquiry among students and teachers in the German language education systems, 2002). Neuried, Germany: Ars Una, 2005.

BORRIES, B. von; KÖRBER, A.; BAECK, O.; KINDERVATER, A. Jugend und Geschichte. Ein europäischer Kulturvergleich aus deutscher Sicht (Youth and history. A comparasion of cultures in Europe from a German perspective). Opladen, Germany: Leske \& Budrich, 1999.

BORRIES, B. von.; WEIDEMANN, S.; BAECK, O.; GRZESKOWIAK, S.; KÖRBER, A. Das Geschichtsbewuztsein Jugendlicher. Erste representative Untersuchung über Vergangenheitsdentungen, Gegenwartwahrnelmugen und Zukunftserwartungen im Ost und Westdentschland (Historical consciousness among adolescents. First representative enquiry about interpretations of the past, observations of the present and expectations of the future in East and West Germany). Weinheim/Müchen, Germany: Juventa, 1995.

DITTMER, L.; SIEGFRIED, D. Spurensucher. Ein Praxisbuch für historische Projektarbeit. (In search of traces. A practical guideline for historical project.). Hamburg, Germany: Edition Körberstiftung, 2005.

GELLNER, E. Nations and nationalism. Ithaca, N.Y.: Cornell University Press, 1983.

HANDRO, S.; SCHÖNEMANN, B. Geschichtsdidaktische Lehrplanforschung. Methoden - Analysen - Perspektiven (Educational research in history curricula. Methods - analyses - perspectives). Münster, Germany: Lit, 2004. 
HROCH, M. Das Europa der Nationen. Die moderne Nationsbildung im europäischen Vergleich (Europe of nations: The rise of nations in modern Europe, a comparative approach). Göttingen, Germany: Vandenhoek, 2005.

JEISMANN, K.; SCHÖNEMANN, B. Geschichte amtlich. Lehrpläbe und Richtlinien der Bundesläbder, Analyse, Vergleich, Kritik (Official History. Curicula and Guidelines of the German Federal States. Analysis, Comparison, Criticism). Frankfurt, Germany: Diesterweg, 1989.

KÖRBER, A.; SCHREIBER, W.; SCHÖNER, A. Kompetenze historischen Denkens. Ein Strukturmodell als Beitrag zur Kompetenzarientierung in der Geschichtsdidaktik (Competences of historical thinking: A structural model as a contribution to the orientation on competences in history teaching). Neuried Germany: Ars Una, 2007.

LEVI-STRAUSS, C. Race and history. Paris: UNESCO, 1952.

LEVI-STRAUSS, C. Race and history. Paris: UNESCO, 1972.

LÜBBE, H. Forschrilt als Orientierungsproblem. (Progress as a problem of orientation). Freiburg: Germany: Herder, 1975.

McNEILL,W. The rise of the West. A history of the human community. Chicago: University of Chicago Press, 1963.

MEBUS, S.; SCHREIBER, W. (Ed.). Geschichte denken statt panken. (Thinking history in steat of rote learning). Meizen, Germany: SALF, 2005.

RÜSEN, J. Historisches Lernen. Grundlagen und Paradimen. (Historical Leraning: Foundations and paradigms.). Köln, Germany: Böhlau, 1994.

SCHREIBER, W.; KÖRBER, A. Historiches Denken. Ein Kompetenz-Strukturmodell. (Historical Thinking: A structural model of competences). Neuried: Ars Una, 2006.

VERBAND DER GESCHICHTSLEHRER DEUTSCHLANDS (Association of History Teachers in Germany). Bildungstandards Geschichte Rahmemmodell Gymnasium 5-10 Jahrgangsstufe. (Attainment targets in history: a framework for the gymnasium grades 5-10). Schwalbach, Germany: Wochenschau, 2006.

WELZER, H. et al. “Was wir für böse Menschen sind!”. Der Narionalsocialismus in Gespräch zwischen den Generationen (How evil we are! National-socialism in the discussion between generations). Tübingen, Germany: Edition Diskord, 1997.

WELZER, H. et al. “Opa war kein Nazi”. Nationalsozialismus und Holocaust in Familiengedächtnis. (Grandpa was not a Nazi. National-socialism and the Holocaust in family memory). Frankfurt, Germany: Fischer, 2002.

Texto recebido em 21 de março de 2016.

Texto aprovado em 27 de março de 2016. 